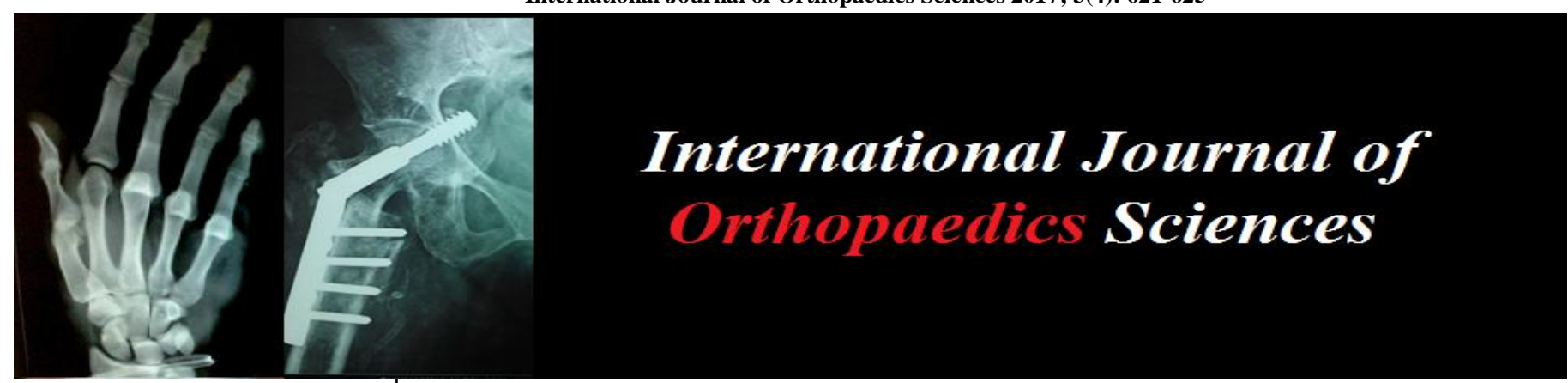

ISSN: $2395-1958$

IJOS 2017; 3(4): 621-625

(C) 2017 IJOS

www.orthopaper.com

Received: 22-08-2017

Accepted: 25-09-2017

Dr. P Maharajothi

MS Ortho, Senior Assistant

Professor, Govt Chengalpattu

Medical College, Chengalpattu,

Tamil Nadu, India
Correspondence

Dr. P Maharajothi

MS Ortho, Senior Assistant

Professor, Govt Chengalpattu

Medical College, Chengalpattu,

Tamil Nadu, India

\section{Free hand technique lumbar spine pedicle screw placement in Indian population office coordinator}

\section{Dr. P Maharajothi}

DOI: https://doi.org/10.22271/ortho.2017.v3.i4i.87

\section{Abstract}

There are different pedicle screws entry point techniques are used for the lumbar pedicle screws placement. This study reported using confluence of pars, mamillary process, midpoint of transverse process, on lateral border of face joint as entry point of lumbar pedicle screws with free hand technique and the accuracy of this technique.

Materials and Methods: A prospective study was done from may 2015 to November 2017 in our hospital using free hand technique lumbar pedicle screw placement includes 50 patients 270 screws. The diagnosis includes degenerative spine, trauma, and spondylolithesis. cortical breach by misplaced pedicle screw was determined by review of computed tomography.

Results: Among the total 270 lumbar free hand placed pedicle screws, 10 screws with lateral breach, 1 screw inferior breach, 2 medial breach without significant neurological involvement with two cases of radicular pain which subsides over period of time without any revision.

Conclusion: Free hand pedicle screw placement based on external landmark using confluence of pars, mamillary process, midpoint of transverse process, on lateral border of face joint as entry point of lumbar pedicle screws with free hand technique and the accuracy of this technique showed acceptable safety and accuracy and avoidance of radiation exposure.

Keywords: Lumbar spine, pedicle screw placement, free hand technique, cortical breach

\section{Introduction}

Pedicle screw fixation has the advantage of utilization in the lumbar spine for superior threecolumn fixation without encroaching into the spinal canal which was used for trauma, instability, degenerative disease and deformity correction ${ }^{[1,2]}$. Its usage has the potential for neurologic deficit, the safety margin for this techniques include the use of anatomical landmarks, laminoforaminotomy, C-arm fluoroscopy, and navigation computer-assisted techniques ${ }^{[3]}$ these techniques through the use of image-guided techniques require additional equipment as well as the use of fluoroscopy which increases the radiation exposure ${ }^{[4]}$.

The use of the free hand technique is to mimic as close as possible the technique of lumbar screw placement without use of any intraoperative fluoroscopy, radiography, and/or imageguided techniques.

This study aimed to evaluate the safety and accuracy of the pedicle screw placement with a free hand technique by analyzing post-operative imaging in the lumbar region.

\section{Materials and Methods}

A prospective study was done from may 2015 to November 2017 in our hospital using free hand technique lumbar pedicle screw placement includes 50 patients 270 screws. The diagnosis includes degenerative spine, trauma, and spondylolithesis.

\section{Surgical technique}

Through posterior approach spine exposed till lateral border of transverse process. Entry made at junction of pars, mamillary process, midpoint of transverse process, on lateral border of face joint. Entry made with bone awl probed with straight gear shift blunt probe with medial angulation 5 degree at 11 and increasing 5 degree additionally 12, 13, 1425 degree at 15. Sagittal angulation in direction of contralateral transverse process. 


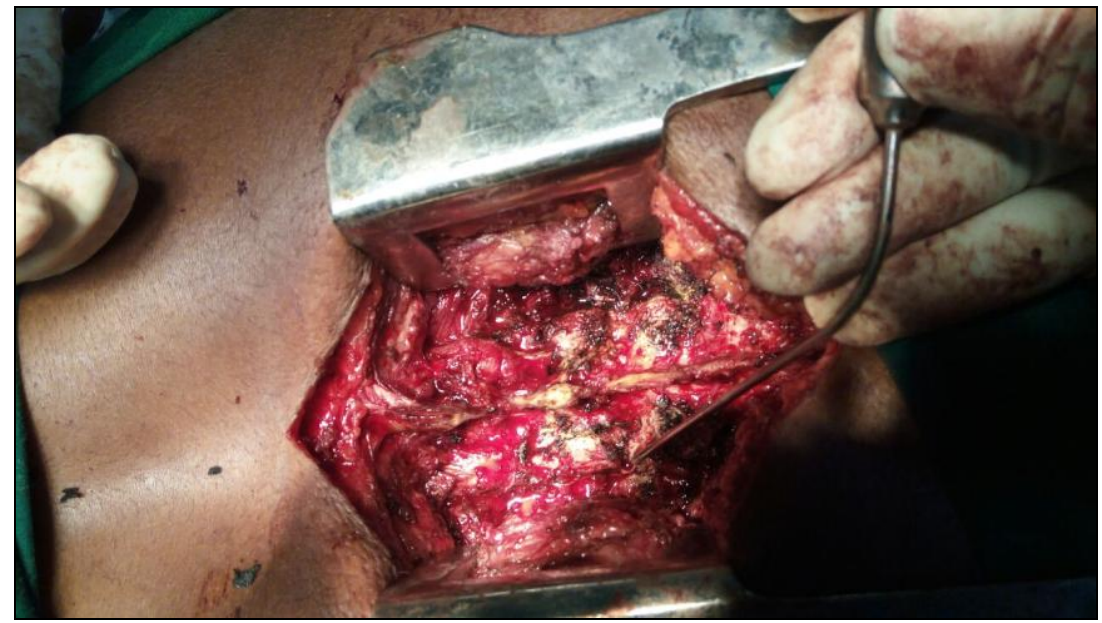

Fig 1: pedicle screw entry point

While entering if there is any resistance direction has to be changed little bit, if there is any free movement it means there is some breach in cortex remove the probe and reinsert with direction change after probing with ball tipped pedicle feeler inserted and checked all four walls superior, inferior, medial and lateral wall and anterior wall should not be penetrated depth measured and screws inserted usually $5.5 \mathrm{~mm}$ to $6.5 \mathrm{~mm}$ diameter screw with length average from 40 to $55 \mathrm{~mm}$ screws used,and connected with rods.
Preoperatively pedicle diameter, length of pedicle and angle measured in CT.

Post operatively CT scan obtained for checking position and detect breach.

CT scans were performed in all patents with follow-up. The CT scans (axial and sagittal) were examined to evaluate the position of screw according to the classification of Learch and Wiesner ${ }^{[5]}$.

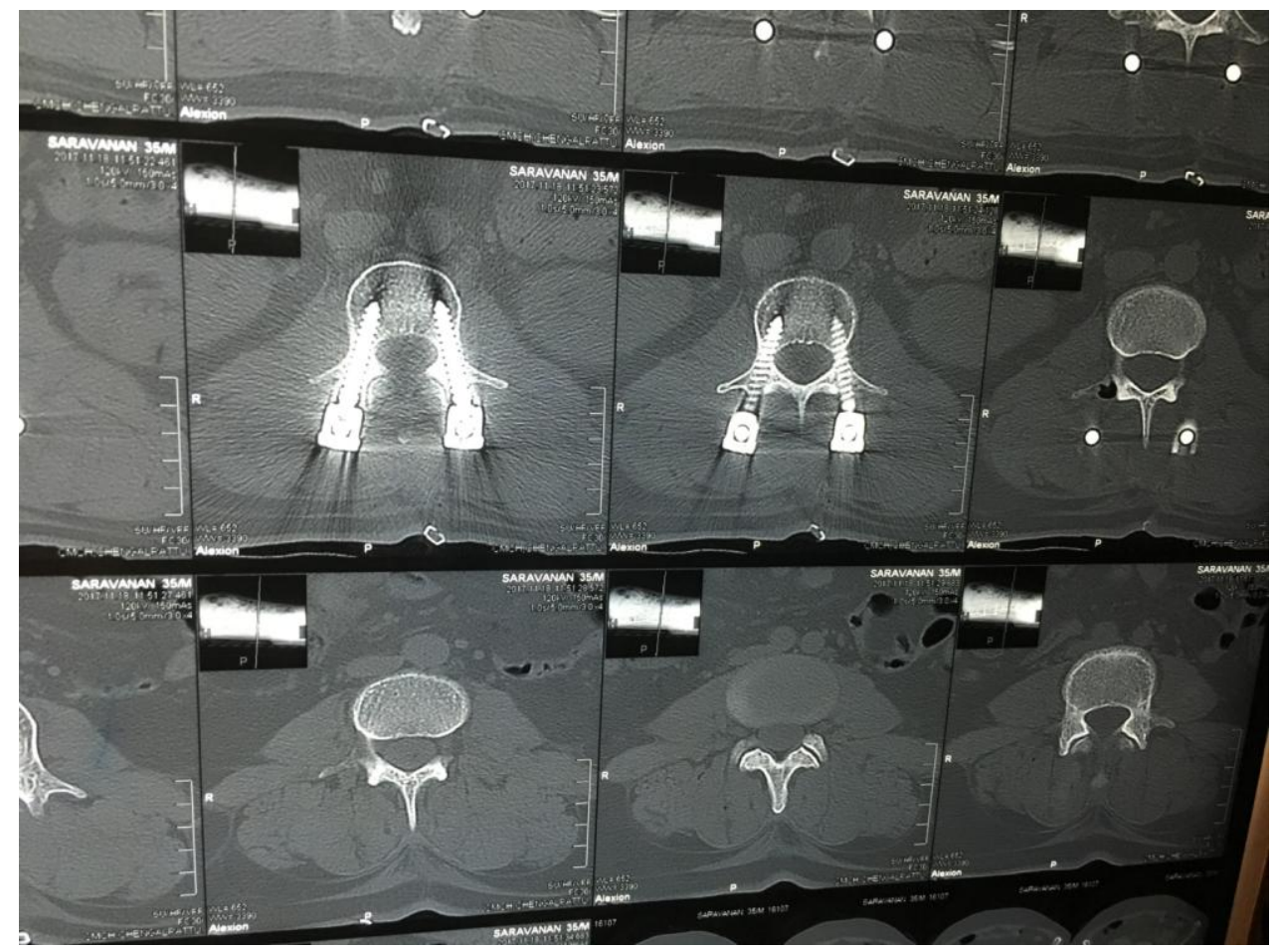

Fig 2: pedicle screw in position

\section{Computed tomography assessment}

Multislice CT scans (axial, sagittal, coronal, and reconstruction) were examined to evaluate the position of the screws according to the classification of Learch et al. and Wiesner et al. In this classification, there are four main categories for screw misplacement.

Grade 0 -Encroachment: the pedicle cortex cannot be visualized.

Grade 1-Minor penetration: the screw trajectory is less than $3 \mathrm{~mm}$ outside the pedicular boundaries.

Grade 2-Moderate penetration: the screw trajectory is 3-6 $\mathrm{mm}$ outside the pedicular boundaries.

Grade 3-Severe penetration: the screw trajectory is more than $6 \mathrm{~mm}$ outside the pedicular boundaries. 


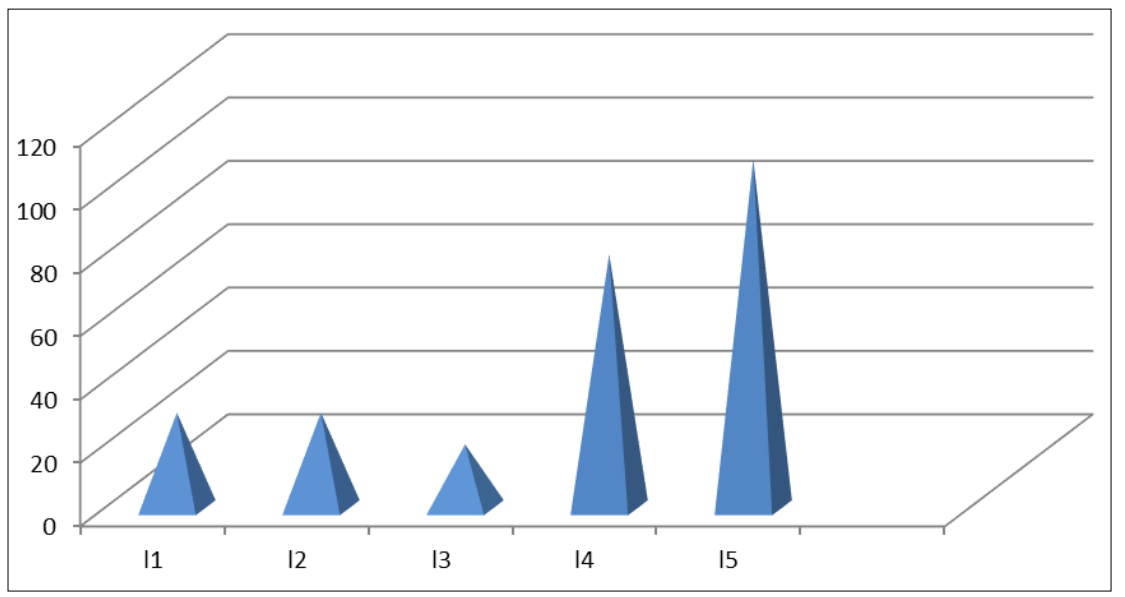

Number of screws 11-30, 12 30, 13 20, 14 80, 15110

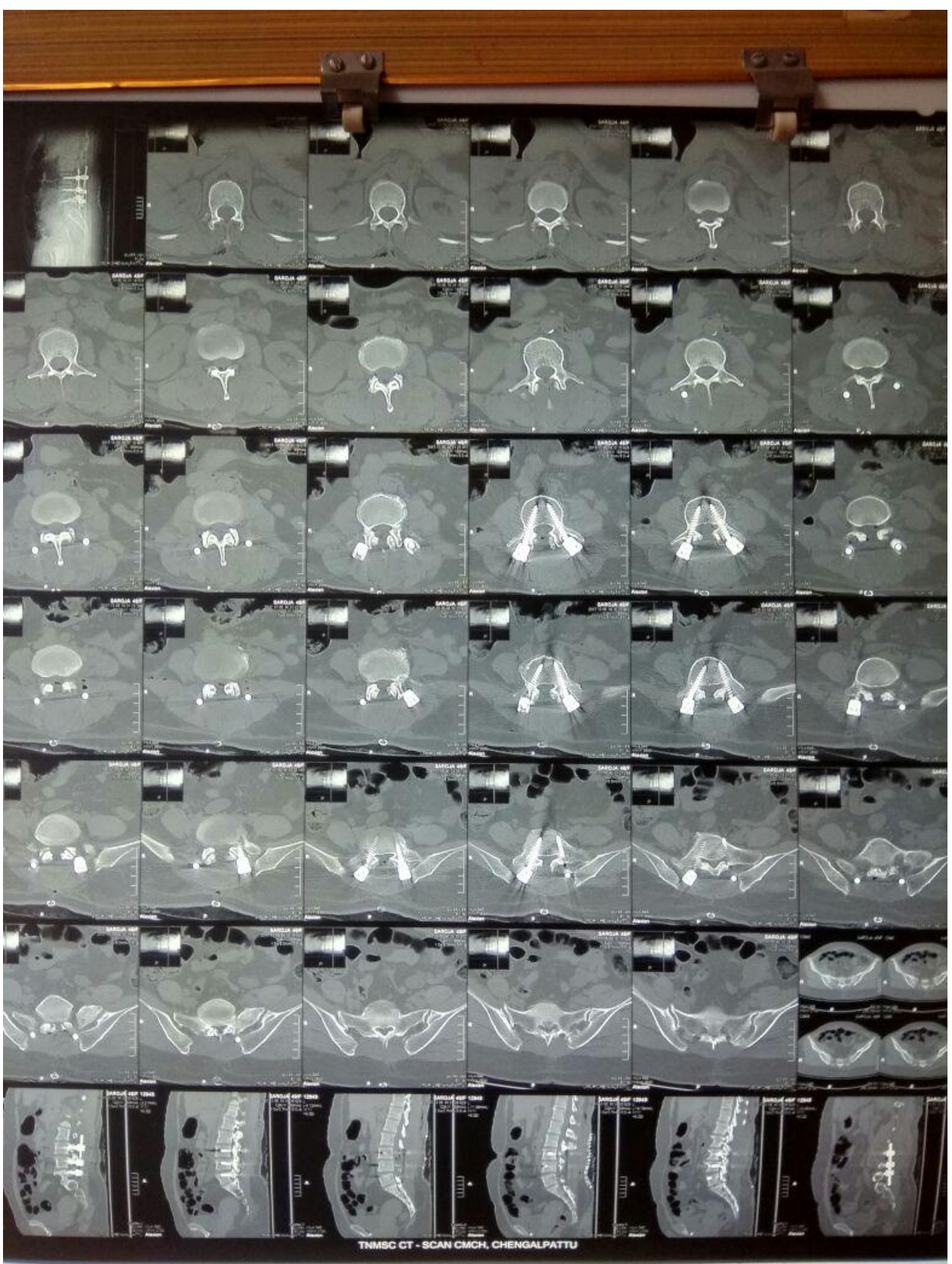

Fig 3: example for pediclescrew without breach 


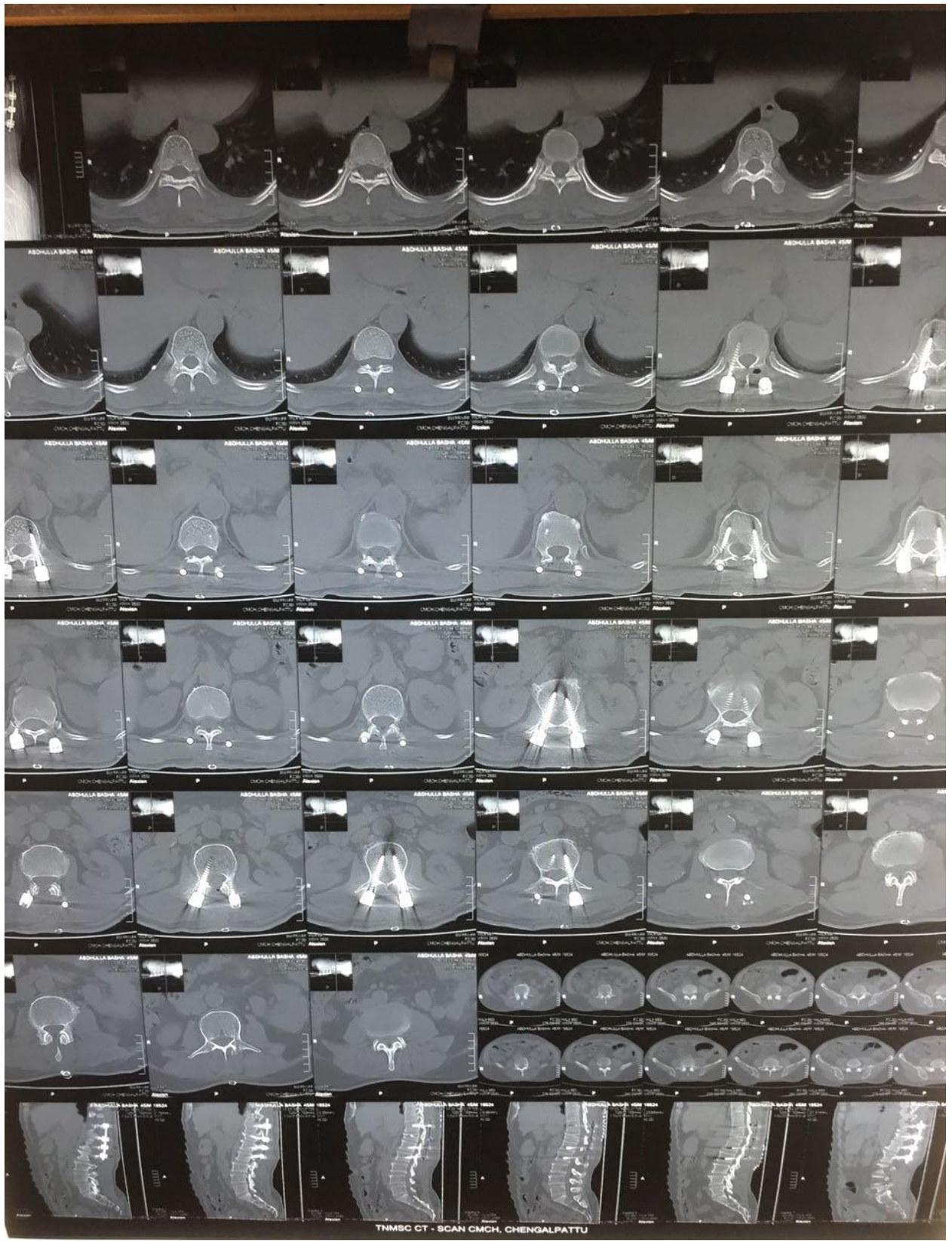

Fig 4: example for post op ct pics

\section{Discussion}

Pedicle screw fixation provides three column strong construct in fractures and instability. Various techniques for this includes free hand technique, fluoroscopy guided, stereotactic navigation assisted and robotic assisted. but they need specialized equipments and also hazardous in form of radiation exposure. Free hand technique needs experience and thorough knowledge of anatomy and experience. the author tried free hand technique after performing more than hundred cases with fluoroscopy assistance. But free hand technique provides accuracy and safety by reducing radiation exposure both to patients and surgeon. our study limits to fracture, spondylolisthesis and degenerative disc disease, our limitation is we have not included scoliosis or kyphosis case in free hand technique.

Cortical breach medially $4 \mathrm{~mm}$ and laterally $6 \mathrm{~mm}$ does not have significant neurological deficit because medialy there is $2 \mathrm{~mm}$ epidural and $2 \mathrm{~mm}$ subarachnoid space which provide safe zone for medial breach in lumbar spine. but even $2 \mathrm{~mm}$ of inferior breach will present with root irritation.

Postoperatively two cases had radiating pain with nerve root irritation but it resolves after 3 weeks. one case had hemiplegia after 5 days of surgery but it has no correlation with surgery. One patient had transverse process fracture. we have not revised any screws. free hand technique in experienced hand produce safety and accuracy with reduced radiation exposure in experienced hands.

\section{Results}

Among the total 270 lumbar free hand placed pedicle screws, 10 screws with lateral breach, 1 screw inferior breach, 2 medial breach without significant neurological involvement with two cases of radicular pain which subsides over period of time without any revision.

\section{Conclusion}

Free hand pedicle screw placement based on external landmark using confluence of pars, mamillary process, midpoint of transverse process, on lateral border of face joint as entry point of lumbar pedicle screws with free hand technique and the accuracy of this technique showed acceptable safety and accuracy and avoidance of radiation exposure in experienced hand. 


\section{References}

1. Hyun SJ, Kim YJ, Cheh G, Yoon SH, Rhim SC. Free hand pedicle screw placement in the thoracic spine without any radiographic guidance: technical note, a cadaveric study. J Korean Neurosurg Soc. 2012; 51:6670. PMID: 22396849

2. Kim YJ, Lenke LG, Cheh G, Riew KD. Evaluation of pedicle screw placement in the deformed spine using intraoperative plain radiographs: a comparison with computerized tomography. Spine (Phila Pa 1976). 2005; 30:2084-2088. PMID: 16166900

3. Cotrel Y, Dubousset J, Guillaumat M. New universal instrumentation in spinal surgery. Clin Orthop Relat Res. 1988; 227:10-23. PMID: 3338200

4. Free-hand. Technique for thoracolumbar pedicle screw instrumentation: Critical appraisal of current State-of-Art Tobias A Mattei, Murilo S Meneses, Jeronimo B Milano $^{2}$, Ricardo Ramina ${ }^{3}$, 2009; 57(6):715-721.

5. El-Fiky T, EL-Razek AA. Three-dimensional assessment of pedicular screws in thoracic and lumbar fractures using free-hand technique: a single-surgeon experience. Egypt Orthop J. 2016; 51:165-9.

6. Roy-Camille R, Sailant G, Mazel C. Plating of thoracic, thoracolumbar, and lumbar injuries with pedicle screw plates. Orthop Clin North Am. 1986; 17:147-59.

7. Learch TJ, Massie JB, Pathria MN, Ahlgren BA, Garfin SR. Assessment of pedicle screw placement utilizing conventional radiography and computed tomography: a proposed systematic approach to improve accuracy of interpretation. Spine (Phila Pa 1976). 2004; 29:767-773. PMID: 15087800

8. Wiesner L, Kothe R, Ruther W. Anatomic evaluation of two different techniques for the percutaneous insertion of pedicle screws in the lumbar spine. Spine (Phila $\mathrm{Pa}$ 1976). 1999; 24:1599-1603. PMID: 10457581

9. Du X, Zhao L. Anatomical study of the adjacent structures to the top point of the $\wedge$ shape crest and its relevance. Chin J Spine Spinal Cord. 2001; 11:89-91. 